\title{
ÉTICA DAS VIRTUDES EM ALASDAIR MACINTYRE: TRADIÇÃO, RACIONALI- DADE E BEM HUMANO ${ }^{1,2}$
}

Helder Buenos Aires de Carvalho (UFPI) ${ }^{3}$

hbac@ufpi.edu.br

Resumo: Uma característica do aparato cultural ocidental contemporâneo é a tematização do ético nas mais diversas esferas da atividade humana, envolvendo desde a ação dos meios de comunicação de massa, passando pela saúde e pela economia, chegando à atividade política, ao desenvolvimento de novas tecnologias e à ecologia. Entretanto, se de um lado isso pode nos apontar otimistamente para um possivel melhoramento do ser humano diante do virulento pluralismo no qual vivemos, ao revelar cada vez mais preocupações e exigências éticas mais amplas e novidadeiras; por outro, esse aparente consenso em torno do ético não pode deixar de nos levar à pergunta a respeito do que está motivando profundamente todo esse aparato cultural a tê-lo como um de seus eixos centrais. $\mathrm{O}$ texto apresenta os pontos centrais da ética das virtudes de Alasdair MacIntyre, buscando mostrar como tradição, racionalidade e bem humanos estão articulados de modo a oferecer uma alternativa às dificuldades de garantir a racionalidade moral no interior do aparato cultural ocidental contemporâneo, frente à força cultural do emotivismo e do relativismo.

Palavras-chave: virtudes; tradição; racionalidade; bem humano; relativismo.

Uma característica do aparato cultural ocidental contemporâneo é a tematização do ético nas mais diversas esferas da

\footnotetext{
${ }^{1}$ Recebido: 05-11-2012/Aprovado: 14-12-2012/Publicado on-line: 29-09-2013.

${ }^{2}$ Texto apresentado como conferencia na XIX Semana de Filosofia da UFG (2012). Partes dele foram previamente publicadas em Peres (2006) e Oliveira (2001).

${ }^{3}$ Helder Buenos Aires de Carvalho é Professor Adjunto na Universidade Federal do Piauí, Teresina, PI, Brasil.
} 
atividade humana, envolvendo desde a ação dos meios de comunicação de massa, passando pela saúde e pela economia, chegando à atividade política, ao desenvolvimento de novas tecnologias e à ecologia. Entretanto, se de um lado isso pode nos apontar otimisticamente para um possível melhoramento do ser humano diante do virulento pluralismo no qual vivemos, ao revelar cada vez mais preocupações e exigências éticas mais amplas e novidadeiras, por outro, esse aparente consenso em torno do ético não pode deixar de nos levar à pergunta a respeito do que está motivando profundamente todo esse aparato cultural a tê-lo como um de seus eixos centrais.

MacIntyre nos provê ferramentas para compreender essa hipertrofia da problematização ética colocando-se na posição de médico da cultura moral ocidental contemporânea, isto é, faz um diagnóstico acerca da condição da sua teoria e prática morais e, a partir daí, oferece um remédio para os males que identifica. Seu diagnóstico é motivado pelo sentimento crítico de que é preciso desconfiar dessa hipervalorização do debate moral em nossa cultura, do fato de que a ética afinal tornou-se uma moda, pois o que isso pode esconder, na verdade, é uma crise profunda. MacIntyre defende certa retomada da ética aristotélica das virtudes com sua busca central pelo bem humano, mas associada a um reposicionamento da tradição como locus da pesquisa racional e estruturando-a a partir de exigências filosóficas atuais, como saída mais eficaz para os problemas que diagnostica na linguagem e na prática morais de nosso século.

Ele se volta para as tradições morais de pesquisa racional como único lugar possível onde a racionalidade dos fins, portanto, das teorias e dos julgamentos éticos, pode 
encontrar um lugar genuíno sem ser dissolvida pela racionalidade dos meios ou reduzida à instrumentalidade de uma vontade arbitrária e alienada, nem também perder seu enraizamento histórico. É com base no vínculo entre tradição e racionalidade que MacIntyre operacionaliza sua crítica à modernidade iluminista e seu projeto ético universalista, ao emotivismo predominante no ethos contemporâneo e à dissolução da racionalidade prática em relações de meio-fim segundo interesses pessoais, às sociedades liberais e seu individualismo inflacionado, que transforma o debate moral em mero jogo irracional de afirmações e contra-afirmações.

\section{A PERDA DO SENTIDO ÉTICO NA MODERNIDADE E A FRAGMENTAÇÃO DO DEBATE MORAL}

A filosofia de MacIntyre opera num nível de generalidade em sua crítica à modernidade liberal, envolvendo uma extensão mais ampla da história cultural e moral do ocidente. Seu foco de análise crítica não é um texto particular da teoria moral ou política contemporânea, mas a origem, o desenvolvimento e o declínio da cultura moral e política ocidental como um todo (MULHALL; SWIFT 1992, 70). MacIntyre se tornou um dos mais eminentes teóricos morais contemporâneos quando publicou "After Virtue" ${ }^{4}$, em 1981, produzindo um giro significativo na filosofia moral e política anglo-saxã, ao articular uma crítica geral da filosofia moral e política moderna com a tese de que conceitos morais são visceralmente vinculados a tradições culturais.

De um lado, durante muitos anos, o filosofar moral anglo-saxão se ateve rigidamente a um formalismo meta-ético,

\footnotetext{
${ }^{4}$ Referências futuras a essas obras serão feitas como AV.
} 
isolando-o de todo engajamento prático, recusando-se a intervir no universo mundano; do outro, o debate político se limitava às querelas internas entre os diversos ramos do liberalismo, de ambiente quase parasitário, sem inovações. Mas com o aparecimento, nos anos 1970, das grandes sínteses ético-políticas no campo liberal e conservador, como os trabalhos de John Rawls e Robert Nozick, se teve o reconhecimento do quanto essas duas tendências se reforçavam mutuamente (SHARKEY 2001, 63). Fato que abriu espaço para uma reação crítica que revelou muito da amplitude e profundidade das dificuldades na relação entre política e moral no pensamento moderno - reação crítica essa que se fez construída parcialmente no comunitarismo. A obra de MacIntyre contribuiu significativamente para o reconhecimento dessas dificuldades, embora ela própria suscite também novas interrogações e desafios.

Elizabeth Anscombe, em seu seminal ensaio "Modern Moral Philosophy" (1958), defendera que o vocabulário moral deontológico da modernidade, calcado no discurso da obrigação e da interdição, tinha perdido seu sentido autêntico, uma vez que a moralidade havia se separado da religião. Segundo ela, todo esse discurso deôntico é derivado de uma concepção legalista da ética, cujos modos de agir têm como fonte e fundamento as prescrições de um legislador divino; entretanto, com o uso de uma linguagem emotivista ou subjetivista na modernidade, tal discurso perdeu sua força de mandamento, se tornando injustificável.

MacIntyre parte dessa tese de Anscombe e a aprofunda em seu diagnóstico da insolubilidade dos conflitos morais da modernidade. De acordo com ele, a moralidade contemporânea é, na verdade, um simulacro de moralidade, uma coleção de fragmentos de moralidades passadas que 
não formam mais um todo coerente. A natureza da comunidade moral e dos juízos morais nas ordens liberais modernas é tal que não é mais possível apelar para critérios morais da mesma forma que teria sido possível em outras épocas e lugares, já que a partir da modernidade perdemos toda a possibilidade conceitual de formular tais critérios de modo integrado e objetivo, perdemos uma concepção unificadora e ordenadora do espaço da moralidade que a tornava inteligível.

É um estado de desordem em que teorias morais rivais, na sua substância incomensuráveis entre si, competem indefinidamente por nossa adesão na arena pública. Ou seja, o problema não é apenas que tais debates morais persistam, mas também que endemicamente não conseguem encontrar um fim. Parece não haver um modo racional de assegurar um acordo moral em nossa cultura, como revela a assustadora variedade de respostas alternativas e incompatíveis que indivíduos e grupos opostos propõem, por exemplo, às questões relativas à justiça. E não adianta recorrer ao domínio da pesquisa teórica, pois se descobrirá que mais uma vez estaremos num cenário de conflito radical, pois o que a filosofia acadêmica moderna consegue oferecer é "uma definição mais exata e melhor informada da discordância do que [...] um progresso na direção de sua resolução" (MACINTYRE 1991, 13) 5 . É um pluralismo moral de natureza superficial, fragmentado, que não é um diálogo ordenado entre pontos de vista que se interseccionam. Há uma superabundância de meios teóricos com os quais podemos formular e justificar racionalmente uma determinada ação moral diante de algum problema, mas esses meios

${ }^{5}$ Referências futuras a essa obra serão como JR. 
proporcionam modos rivais, e incomensuráveis entre si, de formular regras morais e de responder às questões colocadas.

Mas o que conduziu a linguagem e a prática morais contemporâneas a esse estado fragmentado? Segundo MacIntyre, tanto nossa cultura geral como nossa filosofia acadêmica são filhas de uma cultura que não conseguiu resolver seus problemas práticos e filosóficos, cujo fracasso determinou a forma dos nossos atuais problemas filosóficos e sociais práticos: a cultura iluminista, forjada no norte da Europa no século XVIII, e seu fracassado projeto de justificar a moralidade. Esse projeto é descrito como centralmente preocupado em dar à moral uma justificação racional, independente da tutela teológica e das tradições, no intuito de dar-lhe total autonomia na forma de princípios morais universais.

A despeito do fato de que os pensadores iluministas discordassem sobre os princípios que constituiriam tal moralidade universal, eles propagaram a crença de que tais princípios existiam e que a conduta moral teria de estar sujeita à validação ou à crítica inteligível. Entretanto, a própria inexistência de uma grade de valores hegemônicos, a partir da qual os juízos morais pudessem estar de acordo, revelou que este ideal não poderia ser atingido. Para MacIntyre, os pensadores iluministas fracassaram e deviam fracassar nesse intento de fundar uma moralidade universal porque compartilhavam um fundo histórico comum de crenças morais, herdado do seu passado cristão, mas privado do esquema que lhe dava coerência e sustentação: o esquema teleológico da Ética a Nicômaco de Aristóteles.

Nesse esquema há um contraste central entre uma natureza-humana-tal-como-existe (concepção da natureza hu- 
mana no seu estado não instruído, como o homem é - o homem em seu estado bruto) e uma natureza-humana-talcomo-seria-se-realizasse-o-seu-telos (concepção do homem tal como ele seria se realizasse sua natureza essencial - o homem educado e aperfeiçoado). A ética é precisamente a ciência que capacitaria os homens a transitar do estado não instruído para aquele em que realiza plenamente sua essência de ser racional, o seu telos. Os preceitos morais nos dão justamente o caminho certo para sairmos da potencialidade ao ato, para entendermos nossa verdadeira natureza e para alcançarmos nosso verdadeiro fim; eles nos indicam e ordenam as virtudes e vícios, como devemos educar e ordenar nossos desejos e emoções pelo uso de tais preceitos e pelo cultivo de tais hábitos de ação. Há, dessa forma, uma estrutura tríplice nesse esquema moral clássico, cujos termos estão articulados de tal maneira que não poderemos entender o status e as funções de cada um sem referência aos outros ${ }^{6}$.

Entretanto, com o advento das teologias católica jansenista e protestante, se incorpora uma nova concepção de razão degradada em seus poderes, concebida como não podendo mais suprir uma genuína compreensão do verdadeiro fim do homem. Em função da queda original, a razão não tem mais o poder de corrigir nossas paixões, se torna calculadora, podendo falar apenas dos meios, nunca dos fins; abrindo espaço para a afirmação de que nossas crenças se fundam, no final das contas, apenas sobre a natureza, o costume e o hábito.

Iluministas como Kant, Hume, Diderot, Smith e Kierkegaard operaram justamente com esse modelo de razão

\footnotetext{
${ }^{6}$ E, segundo MacIntyre, esse esquema não é alterado substancialmente quando colocado dentro da estrutura de crenças teístas, seja na sua forma cristã, judaica ou islâmica, uma vez que a natureza triádica do esquema permanece central ao entendimento teísta dos juízos e pensamentos valorativos.
} 
empobrecida nos seus poderes, incapaz de discernir naturezas essenciais ou traços teleológicos no mundo objetivo. Com isso, se, de um lado, há um desacordo entre esses autores quanto à definição da natureza humana, de outro há um surpreendente acordo em torno dessa mesma definição no seu aspecto negativo, pois "todos rejeitam qualquer visão teleológica da natureza humana, qualquer visão do homem como tendo uma essência que define seu verdadeiro fim” (AV, 54).

E é justamente a rejeição secular tanto da teologia católica como da protestante - que ainda retinham o elemento teleológico do esquema clássico -, somada à rejeição científica e filosófica do aristotelismo, que pulverizou toda possibilidade de qualquer noção do homem-como-seria-serealizasse-o-seu-telos. Essa eliminação de qualquer concepção da natureza essencial do homem e do seu telos fez com que se produzisse um esquema moral composto de dois elementos, remanescentes do esquema clássico, cujas relações internas tornam-se agora inteiramente confusas ${ }^{7}$. Sem a noção de um telos para que os preceitos morais cumpram sua função mediadora de passagem do estado original para a realização da essência do homem, as injunções da moralidade se transformam em preceitos que vão de encontro às tendências da natureza humana concebida não teleologicamente.

Com isso, ao estabelecerem um corte entre os preceitos da moralidade e os fatos acerca da natureza humana, os pensadores iluministas produziram uma mudança radical no caráter da moralidade e da linguagem moral da qual, paradoxalmente, não conseguiram perceber todo o alcance.

\footnotetext{
7 "Há, de um lado, um certo conteúdo para a moralidade: um conjunto de injunções desprovidas de seu contexto teleológico. De outro lado, há uma certa visão da natureza-humana-como-ela-é-não-educada." (AV, 55)
} 
Filósofos como Kant, Diderot, Hume e Kierkegaard acabaram por desenvolver uma argumentação negativa que reforçava uma versão da tese de que nenhum argumento válido pode passar de premissas inteiramente factuais para conclusões valorativas ou morais, quer dizer, reforçaram, ao final das contas, um princípio que "uma vez aceito constitui o epitáfio ao projeto inteiro deles" (AV, 56).

O fracasso do projeto iluminista demarcou toda a problemática da teoria moral moderna fazendo-a girar em torno da necessidade de devolver a validade racional às regras morais. Quando, de um lado, liberou o agente moral de todo e qualquer vínculo com hierarquias e teleologias, tornando-o autônomo e soberano na determinação dos conteúdos morais; e, de outro, transformou as regras morais de tal forma que elas perderam o estatuto factual e categórico que possuíam e se tornaram meros instrumentos dos desejos e vontades arbitrários de um agente moral individual, o Iluminismo tornou agudo o problema de se encontrar uma nova teleologia ou um novo estatuto categórico para as regras da moralidade, de tal forma que o recurso a elas se tornasse novamente racional e, ao mesmo tempo, se mantivesse a autonomia do agente moral individual.

O fracasso do utilitarismo da metade e do final do século XIX e da filosofia moral analítica alimentada por pretensões kantianas da metade e do final do século XX, ao enfrentarem essa problemática pós-iluminista, nos revela, segundo MacIntyre, justamente a incoerência presente no esquema moral do século XX. Apesar do fracasso dessas duas tentativas de resgatar o agente moral individual do esvaziamento e da perda da validade racional para os seus proferimentos morais, quase todo mundo, tanto filósofos 
como não filósofos, ainda continua a falar e a escrever como se um desses projetos de devolver racionalidade à linguagem moral tivesse dado certo. $\mathrm{Na}$ verdade, o fosso emotivista entre o significado das expressões morais e o uso que é feito delas origina-se justamente do fracasso de ambos os projetos, pois se um deles tivesse sido bem-sucedido o significado da linguagem moral herdada da tradição teria sido mantido e sustentada sua validade racional. Como, na avaliação de MacIntyre, nenhum desses dois projetos deu certo, então o uso emotivista da linguagem e dos conceitos morais foi a consequência se não necessária, pelo menos esperada ${ }^{8}$.

Mas a principal consequência do fracasso do projeto iluminista de justificação racional da moralidade que MacIntyre aponta para a cultura das sociedades contemporâneas é o dilema a que ele conduziu: sustentar o projeto nietzschiano de uma crítica radical da moralidade ou retomar a perspectiva da ética aristotélica das virtudes como forma de devolver coerência e racionalidade ao desacordo moral que reina na cultura moderna. MacIntyre vê a análise nietzschiana da moralidade como o resultado maior do projeto iluminista de um sujeito moral autônomo concebido à parte e anteriormente à sociabilidade histórica, pois Nietzsche teve o mérito e a coragem de radicalizar conscientemente o fracasso do projeto iluminista de uma moralidade universal racional.

Melhor que qualquer outro pensador, ele percebeu que a linguagem moral na modernidade estava disponível para qualquer uso, que a moral podia agora ser utilizada para um

\footnotetext{
${ }^{8}$ Emotivismo é a tese de que todo discurso moral é somente expressão de sentimentos, sem conteúdo racional.
} 
número considerável de causas, que a forma dos proferimentos morais modernos fornecia uma máscara possível para qualquer rosto. Nietzsche entendeu claramente que aquilo que na linguagem moral do Iluminismo parecia ser apelo à objetividade era, de fato, expressão da vontade subjetiva; e percebeu também a natureza dos problemas que isto colocava para a filosofia moral ${ }^{9}$. Seu maior mérito foi ter enfrentado sem medo o problema gerado pela destruição do projeto moral iluminista: justamente o que erigir no seu lugar, o problema de como construir, de modo original, uma nova tábua de valores que não fosse mais aquela máscara autoenganadora projetada pelos protagonistas do Iluminismo ${ }^{10}$.

Nietzsche acrescentou à sua crítica das moralidades iluministas a percepção do fracasso delas em dar um tratamento adequado à questão: que tipo de pessoa eu vou me tornar? Noutras palavras, que virtudes eu tenho de adquirir? Como vou modelar o meu caráter? Esta é, de certa maneira, uma questão inescusável, à qual uma resposta é dada na prática por cada vida humana. Mas para as moralidades caracteristicamente modernas esta é uma questão a ser abordada somente indiretamente, pois a questão primordial para elas se refere às regras: quais regras devemos seguir? E porque devemos obedecê-las? A esse dilema que se coloca diante da cultura contemporânea, MacIntyre pretende oferecer uma resposta na qual as virtudes passem a ocupar um papel central na configuração da moralidade, na qual regras

\footnotetext{
${ }^{9}$ Para MacIntyre, o erro de Nietzsche foi ter generalizado a condição do juízo moral em seu próprio tempo para a natureza da moralidade enquanto tal.

10 "Este problema constituiria o núcleo central de uma filosofia moral nietzscheana. Pois é na sua implacavelmente séria perseguição do problema, não nas suas frívolas soluções, que reside a grandeza de Nietzsche, grandeza que faz dele o filósofo moral se as únicas alternativas à filosofia moral de Nietzsche mostrarem-se ser aquelas formuladas pelos filósofos do Iluminismo e seus sucessores." (AV, 114)
} 
e princípios passem a ter sentido no interior de uma definição partilhada socialmente do bem último do homem, exercitada e construída em comunidades históricas.

\section{ARISTÓTElES, TRADIÇÕES DE PESQUiSA, TELEOLOGIAS, VIRTUDES E PRÁTICAS}

MacIntyre vê a saída para o dilema Aristóteles-Nietzsche em uma retomada do espírito geral da psicologia moral aristotélica na perspectiva de uma tradição de pesquisa racional. Quer dizer, encarar a filosofia moral de Aristóteles como o núcleo central de uma tradição de pesquisa e de prática social, da qual ele não é o único representante, ainda que seja quem forneceu os principais parâmetros de sua formulação e desenvolvimento. Nesse sentido, a significação moral dos atos não derivará dos resultados produzidos, cujo valor seria anterior aos princípios morais, como afirma o utilitarismo, nem em uma conformidade a princípios abstratos da razão pura prática, como querem os kantianos.

Segundo MacIntyre, a moralidade reside nas disposições de caráter, adquiridas pelo hábito, cujo estatuto de virtudes se caracteriza exatamente pela sua orientação para fins constitutivos da boa vida humana. Assim, se quisermos restituir a coerência à moralidade, é preciso nos reportarmos a essa condição da vida humana como sendo teleologicamente ordenada. Esse ordenamento vai ser encontrado no âmbito das práticas sociais, não em invariantes naturais. Em seu neo-aristotelismo, MacIntyre transforma a questão "O que devo fazer?" em "Que tipo de pessoa devo me tornar?" ou, ainda, "Qual gênero de vida devo levar?". Com isso, o âmbito da pergunta moral não se restringe a atos individuais, como o liberalismo preconiza, mas se abre para a forma 
de vida na qual tais atos se realizam e para o caráter do agente moral, para a forma de vida coletiva necessária para sua sustentação, para as comunidades e suas tradições de pesquisa racional intrínsecas.

Nessa perspectiva, o caráter do sujeito moral é formado e se desenvolve num contexto social determinado, pela participação nas práticas constituídas em torno dos fins de cada tradição, nas quais a maturidade moral é adquirida pela reflexão sobre o gênero de vida vivenciado e pela avaliação das ações como vícios ou virtudes, fracassos ou sucessos, por meio de uma narrativa pessoal construída no interior de uma tradição de pesquisa constituída pela comunidade e dela constitutiva. Assim, a identidade moral e o valor moral das ações dos indivíduos estão relacionados às práticas das tradições racionais e às formas sociais, comunitárias, de sua cultura $^{11}$.

MacIntyre opera aqui o conceito de tradição, não como algo passado estaticamente através das gerações e que se manifesta imutavelmente na vida social e cultural das comunidades que vivem sob o seu signo, mas sim como portadora de uma dinâmica interna, na qual o conflito tem um lugar necessário na sua constituição. A tradição, para ele, é

uma argumentação, desenvolvida ao longo do tempo, na qual certos acordos fundamentais são definidos e redefinidos em termos de dois tipos de conflitos: os conflitos com críticos e inimigos externos à tradição, que rejeitam todos ou pelo menos partes essenciais dos

\footnotetext{
${ }^{11}$ Uma perspectiva bem diferente da modernidade liberal, que não oferece uma cultura unificada, ou seja, não tem um conjunto comum de valores e virtudes compartilhados que permitiriam a avaliação das ações, instalando o desacordo insolúvel no âmbito prático. Segundo MacIntyre, "a retórica dos valores comuns tem uma grande importância ideológica, mas ela maquia a verdade quanto à maneira com que a ação é guiada e dirigida. Porque o que, em nossas máximas, preceitos e princípios morais, nos é verdadeiramente comum é insuficientemente determinado para guiar a ação, e o que é suficientemente determinado para orientála não nos é comum" (MACINTYRE 1994, 6).
} 
acordos fundamentais, e os debates internos, interpretativos, através dos quais o significado e a razão dos acordos fundamentais são expressos e por cujo progresso uma tradição é constituída. (JR, 23)

Para entendermos corretamente o que é uma tradição de pesquisa racional, precisamos abandonar os usos ideológicos que o conceito de tradição tem recebido de teóricos conservadores ao contrastarem tradição e razão, estabilidade da tradição e conflito. Ao contrário, o raciocínio de um agente moral sempre acontece no interior de algum modo tradicional de pensamento, isto é, o espaço da racionalidade é o espaço interno da tradição. Uma tradição em bom estado não significa ser algo estável e perene, imóvel nas suas formulações, ao contrário, é sempre constituída parcialmente por uma discussão em torno dos bens cuja busca dá sentido e propósito a essa tradição. A pesquisa racional é sempre uma linha de discussão em torno dos bens internos à tradição social mais ampla da qual ela é constitutiva e pela qual é constituída. Daí porque tradições vivas serem continuidade de conflitos, uma discussão historicamente estendida e socialmente encarnada, uma discussão precisamente acerca dos bens que constituem essa tradição.

Para MacIntyre, é sempre um tipo particular de prática que providencia o contexto no qual as virtudes morais vão ser exibidas e definidas. A "prática" é definida, diferentemente do uso ordinário da palavra, como toda forma complexa e coerente de atividade humana coletiva, estabelecida socialmente, por meio da qual

bens internos são realizados na busca de alcançar aqueles padrões de excelência que são apropriados e parcialmente definidores dessa forma de atividade, resultando que os poderes humanos para alcançar a excelência, e as concepções dos fins e bens envolvidos, são sistematicamente ampliados. (AV, 187) 
Nesse sentido, dar um chute com habilidade numa bola não é uma prática, mas o jogo de futebol é; plantar batatas não é uma prática, mas a agricultura é; levantar paredes não é uma prática, mas a arquitetura é. E assim são práticas as pesquisas da física, química e biologia, o trabalho do historiador, a pintura e a música, etc., uma variedade ampla que abrange desde artes, ciência, jogos, política, até a formação e a sustentação da vida familiar.

Para MacIntyre, a vida individual consiste na unidade de uma narrativa encarnada numa vida singular, que, na forma de atos e palavras, tenta responder sistematicamente às questões acerca do que é bom para cada indivíduo e do que é bom para o homem a partir do interior das práticas. É o tecido histórico dos significados formado pelas respostas a essas duas questões que constitui a unidade da vida moral tanto para um indivíduo como para a comunidade. Mais precisamente, a unidade de uma vida humana é a unidade de um relato de busca:

Buscas algumas vezes fracassam, são frustradas, abandonadas ou dissipadas em distrações, e as vidas humanas podem, de todos esses modos, também fracassarem. Mas o único critério para sucesso ou fracasso numa vida humana tomada como um todo são os critérios de sucesso ou fracasso numa busca narrada ou a ser narrada. (AV, 219)

Uma busca orientada por um telos, mais precisamente por alguma concepção do bem para o homem que nos permita ordenar outros bens, ampliar nossa compreensão do propósito e conteúdo das virtudes, entender o lugar da integridade e da constância na vida, definindo, com isso, ao final, o tipo de vida que é uma busca pelo bem. Mas uma busca pelo bem não como algo já definido e pronto, como que situado em patamares transcendentais, e sim envolven- 
do um aprendizado contínuo em relação tanto ao caráter desse bem como também em relação ao autoconhecimento do próprio agente moral. Quer dizer, é no próprio processo histórico da busca, de enfrentamento dos perigos, ameaças, tentações e distrações particulares envolvidas nessa trajetória, com seus episódios e incidentes peculiares, que o objetivo da busca vai ser entendido.

As virtudes vão ser definidas exatamente como aquelas disposições que darão sustentáculo às práticas e nos habilitam a alcançar seus bens internos, mas "que também nos manterão no tipo relevante de busca pelo bem, habilitandonos a superar os perigos, ameaças, tentações e distrações que encontraremos, e que nos fornecerão um crescente autoconhecimento e um crescente conhecimento do bem". Com isso MacIntyre pode, então, nos oferecer uma definição, provisória, do que significa a boa vida para o homem, isto é, do telos que orienta a ação do homem numa vida humana considerada como um todo: "a boa vida para o homem é a vida gasta procurando a boa vida para o homem, e as virtudes necessárias para esse procurar são aquelas que nos capacitarão a entender o que mais e mais é a boa vida para o homem" (AV, 219; AV, 219).

Mas essa definição da boa vida para o homem e do papel das virtudes na busca dessa boa vida ainda exige um último passo. $\mathrm{E}$ isso tem a ver com o fato de que tanto a busca pelo bem como o exercício das virtudes não pode ser procurada por cada um de nós somente enquanto indivíduos, como se estivéssemos isolados das comunidades históricas a que pertencemos e das quais derivamos nossa identidade. Por isso MacIntyre concebe a reflexão moral como um enclave teórico entre a filosofia, a sociologia e a história, quer dizer, não se pode pensar o agente moral e 
sua identidade fora dos âmbitos sociais e da história narrada da qual ele faz parte.

Nesse sentido, a conceituação da virtude também não pode estar fora dessa tríplice determinação, seu papel e função também têm de ser definidos em torno desses mesmos elementos. Viver a boa vida varia concretamente em função das circunstâncias - mesmo quando é a mesma concepção da boa vida e o mesmo conjunto de virtudes que estão encarnados numa vida humana - não apenas porque somos indivíduos diferentes vivendo circunstâncias diferentes, mas porque carregamos uma identidade social particular. Isso significa dizer que a minha identidade, o meu eu, não pode ser separado dos papéis e do status social e histórico que vivencio, pois a história da minha vida está inserida na história daquelas comunidades das quais retiro minha identidade.

Entretanto, MacIntyre adverte que o fato do eu encontrar sua identidade moral mediante seu pertencer a comunidades como a família, a vizinhança, a cidade e a tribo não significa que esteja preso às limitações da particularidade daquelas formas de comunidade, que não possua qualquer capacidade crítica e esteja condenado às determinações da particularidade social em que está mergulhado. Essas particularidades morais constituem o dado inicial, o ponto de onde começar a mover-se, a lançar-se para além de tais particularidades na busca do bem, do universal; mas uma busca na qual a particularidade nunca vai poder ser deixada para trás ou obliterada. Para MacIntyre, a tentativa iluminista de escapar da particularidade mergulhando num campo de máximas inteiramente universais pertencentes ao 
homem enquanto tal é uma ilusão que tem consequências terríveis ${ }^{12}$.

Quer dizer, a minha identidade, aquilo que sou é em grande parte oriundo do que herdei, de um passado específico que está presente de alguma forma no meu presente, porque sou parte de uma história, uma história que, reconhecendo ou não, gostando ou não, é um dos sustentáculos de uma tradição. Mas tradição entendida aqui como uma discussão historicamente estendida e encarnada socialmente, em parte acerca dos bens que constituem a tradição, dos bens cuja busca lhes dá sentido e propósito. Ou seja, MacIntyre se refere às tradições sociais mais amplas que se construíram historicamente como formas de vida portadoras de um vívido debate interno em torno do que seja a boa vida e o bem para o homem.

Uma tradição, nesse sentido, é uma história de conflitos, é uma narrativa dos debates que conduziram a sua formulação ao estágio atual; uma tradição é o terreno no qual todo e qualquer raciocínio tem lugar, transcendendo por meio da crítica e da invenção as limitações do que foi até aqui pensado nessa tradição, isso valendo tanto para a física como para a lógica medieval, numa busca dos bens que se estende muitas vezes por muitas gerações. Da mesma forma que a busca de cada indivíduo pelo seu bem está, de um modo geral, inserida dentro do contexto definido pelas tradições das quais a vida do indivíduo faz parte, assim também ocorre com os bens internos às práticas e os bens de uma vida particular. Como as tradições têm um caráter his-

\footnotetext{
${ }^{12}$ Segundo ele, "quando homens e mulheres identificam o que são, de fato, suas causas particulares e parciais muito parcialmente e muito completamente com a causa de algum princípio universal, eles usualmente comportam-se piores do que se comportariam de outra forma" (AV, 221). Totalitarismo, etnocentrismo, preconceitos raciais e culturais são exemplos dessas ilusões universalistas.
} 
tórico, nunca são estáticas nas suas formulações, sofrem um processo permanente de recriação e transformação, não significa necessariamente que vão existir e permanecer ad eternum, elas também podem decair, desintegrar e desaparecer. $\mathrm{O}$ que vai sustentar e reforçar ou enfraquecer e destruir uma tradição é precisamente o exercício ou a falta do exercício das virtudes relevantes.

\section{RELATIVISMO, RACIONALIDADE DAS TRADIÇÕES E JUSTIFICAÇÃO HISTÓRICA}

Haveria, nesse sentido, um relativismo em MacIntyre? Se os critérios de avaliação moral não são instâncias extramorais incontestáveis nem princípios a-históricos da razão prática, mas são imanentes às tradições e práticas sociais particulares nas quais os agentes estão inseridos, como se evitaria o relativismo? Se não há uma instância fora das tradições que permita avaliar a moralidade preconizada numa tradição particular de práticas sociais e de pesquisa, o risco de relativismo parece emergir com força, não sendo apenas retórico. E se a ordem política do Estado não respeita os valores de uma determinada tradição de pesquisa moral, como eles deverão agir? Se tais tradições são expressões racionais de comunidades particulares de práticas, como essas comunidades subsistem e atuam no interior do moderno Estado liberal, negador das tradições e de concepções teleológicas do bem humano? (HALDANE 1994, 890).

$\mathrm{O}$ primeiro conjunto de questões têm recebido uma atenção central de MacIntyre. E sua resposta tem sido a de que precisamos recuperar justamente aquilo que o Iluminismo nos privou, isto é, uma concepção da pesquisa racional que seja inseparável da tradição social e intelectual em 
que está incorporada, na qual "os próprios padrões de justificação avultem e façam parte de uma história na qual eles sejam exigidos pelo modo como transcendem as limitações e fornecem soluções para as insuficiências de seus predecessores, dentro da história dessa mesma tradição" (JR, 18). A proposta de MacIntyre é articular e justificar uma teoria ética vinculada à tradição por meio de uma concepção da racionalidade prática também vinculada à tradição, mas que, ao mesmo tempo, essa racionalidade não seja relativa, isto é, que não é a priori incomensurável com concepções de racionalidade alternativas de outras tradições.

Uma racionalidade que encontra seu sentido e funcionalidade no interior de uma tradição particular, mas que é capaz de enfrentar e se abrir às posições de suas rivais, não se engessando nos seus próprios termos, nem paralisando o debate que seu encontro com essas alternativas rivais gera como necessário para a afirmação de seu próprio progresso e crescimento - encontro esse que pode até resultar em sua própria destruição. Uma racionalidade que possibilita que essa tradição, por sua vez, se aproprie de recursos teóricos que não são originalmente seus e que são inicialmente alheios ao seu esquema conceitual, para com isso enfrentar mais qualificadamente os problemas que atravessam sua trajetória histórica.

Nessa concepção de pesquisa racional, a justificação racional é um empreendimento essencialmente histórico, forjada no interior de uma tradição social e intelectual particular como uma narrativa que dá conta de como os princípios primeiros das teorias, constituídos pela tradição e constitutivos dela, foram estruturados e construídos, de como eles chegaram a ser o que são hoje. Numa tradição de pesquisa e de justificação racionais, as teorias são construí- 
das de tal maneira que certas teses tem o estatuto de primeiros princípios, a partir dos quais todos os outros elementos teóricos vão ser justificados por derivação deles.

Tais primeiros princípios e, por conseguinte, toda a estrutura da teoria da qual fazem parte, são justificados não por meio de sua aceitação universal e absoluta por toda e qualquer pessoa presumivelmente racional com base em critérios neutros, mas sim por meio da superioridade racional da estrutura atual em relação a todas as outras tentativas anteriores de formular tais princípios e teorias no interior dessa tradição particular, como também em relação ao confronto com os adversários externos à tradição que rejeitam seus acordos internos fundamentais. Nesse sentido, a justificação racional vai ser uma narrativa histórica da pesquisa e do debate no interior da tradição e também uma narrativa do debate e da discordância com as tradições adversárias, debates esses que permitem a identificação adequada dos compromissos da tradição em particular, da sustentação adequada ou não dos primeiros princípios, que são constitutivos e constituintes da racionalidade dessa tradição.

Mas no caso de concepções de moralidade e de racionalidade prática propostas em esquemas conceituais rivais, que empregam modos de caracterização e argumentação por vezes totalmente diferentes e incompatíveis, como, então, decidir entre posições rivais e mutuamente exclusivas se não há um padrão neutro independente de qualquer tradição e racionalmente justificável ao qual possamos recorrer? Aqui, pretende MacIntyre, o reconhecimento da diversidade de tradições de pesquisa, cada uma com seu modo específico de justificação racional, não implica necessariamente que as divergências não possam ser racionalmente resolvidas, pois "do ponto de vista das tradições de pesquisa raci- 
onal, o problema da diversidade não é abolido, mas transformado, de maneira a viabilizar sua solução" (JR, 20).

Nos conflitos e debates entre tradições rivais, no qual o desacordo é sistemático de tal maneira que aparentemente elimina a possibilidade de qualquer padrão comum para a resolução racional do desacordo, cada uma das tradições rivais terá sua própria problemática interna, seus momentos de incoerência, seus problemas não resolvidos, julgados segundo seus próprios padrões do que é problemático, do que é coerente e do que é uma solução satisfatória, padrões esses explicitados na narrativa histórica que lhe é constitutiva. A superioridade racional do ponto de vista filosófico de uma tradição sobre outra é, então, a habilidade deste de transcender as limitações daquele outro,

providenciando de seu próprio ponto de vista uma explicação e entendimento melhor dos fracassos, frustrações e incoerências do outro ponto de vista (fracassos, frustrações e incoerências, isto é, tal como julgados pelos padrões internos àquele outro ponto de vista) do que aquele outro ponto de vista pode dar de si mesmo, de tal forma que nos capacita a dar uma melhor interpretação histórica, uma narrativa verdadeira mais adequada e inteligivel daquele outro ponto de vista e seus sucessos e fracassos do que ele pode providenciar para si mesmo. (MACINTYRE 1984, 47)

Resulta que, assim como as conquistas das ciências naturais vão, ao final de tudo, ser julgadas nos termos das conquistas da história daquelas ciências, também as conquistas da filosofia moral vão ser avaliadas, no final das contas, nos termos das realizações da história da filosofia moral. Dessa forma, julgando as teorias morais em termos históricos, MacIntyre crê superar o desafio do ceticismo nietzschiano, ao mesmo tempo abandonando as posições assumidas pelo absolutismo dogmático. O que nos capacita a fazer uma avaliação e uma escolha racional e objetiva entre 
teorias competidoras, morais ou científicas, não é aplicar padrões absolutos, mas somente padrões históricos. É somente inoculando uma perspectiva histórica que teremos bases racionais para mudar de uma teoria para outra, sem contudo ter de mostrá-la como válida em termos absolutos; é somente localizando as teorias na história, "quando visamos as demandas por justificação em contextos muito particulares de tipo histórico, que estamos livres do dogmatismo ou da capitulação ao ceticismo" (MACINTYRE 1977, 471).

\section{A TÍTULO DE CONCLUSÃO}

Para MacIntyre, os problemas na teoria e prática morais de nosso tempo são resultantes da dissolução crescente e da agudíssima crise do paradigma universalista das sociedades herdeiras da cultura iluminista. É o fracasso desse paradigma, depois de três séculos e meio de tentativas malsucedidas, que está nas raízes de nossas dificuldades. Dificuldades que começaram quando a modernidade abandonou o paradigma teleológico aristotélico da moralidade e lançou toda a linguagem e a prática morais na busca de padrões universais neutros, a-históricos, cuja validade se colocava acima das tradições morais e sociais, desembocando no buraco negro do emotivismo contemporâneo que dissolve toda a racionalidade prática em nome de um subjetivismo autofágico e incoerente. Nesse sentido, a crise moral contemporânea só pode ser solucionada se retomarmos esse paradigma anterior à modernidade - e que sobreviveu às margens das modernas sociedades liberais - reformulado segundo as exigências epistemológicas e sociais contemporâneas, de tal maneira que a teoria e a prática morais recu- 
perem sua qualidade racional e deixem essa aparência de pluralismo fraudulentamente persistente.

Somente um paradigma de racionalidade ética que encarne a contingência e a natureza histórica da teoria e da prática morais, bem como sua indissociabilidade com uma ordem social, portanto, que se estruture e se reconheça como uma tradição moral de pesquisa racional, é que vai ser capaz de desvelar a especificidade de nossas dificuldades no cenário moral e oferecer uma solução substancial para os problemas de irracionalismo que enfrentamos na vida moral de nossas sociedades. Para MacIntyre, somente o retomar da ética aristotélica das virtudes como uma tradição moral de pesquisa racional assume tal perspectiva e vai nos aportar os recursos conceituais para enfrentar o desafio que Nietzsche colocou para toda e qualquer filosofia moral em nossa época: a de não se mostrar como máscara de uma vontade de potência. Somente o restabelecimento do paradigma da tradição das virtudes vai permitir que o agir e o pensar morais readquiram a qualidade racional, fundada numa visão do telos humano construída como uma narrativa histórica que situa as ações morais no quadro de um conjunto de princípios e padrões racionais resultantes de debates internos e externos, formulados no enfrentamento das crises e questões emergidas no interior das práticas constitutivas da tradição de pesquisa e ação moral.

Nesse sentido, podemos perceber que sua retomada da ética aristotélica das virtudes é feita com uma instrumentação conceitual contemporânea. Ele é filosoficamente um pensador contemporâneo, a despeito de valorizar um instrumental teórico que tem raízes na Grécia antiga e que julga ainda poder contribuir para a solução de nossos problemas. Sua reflexão oferece uma alternativa razoável, 
embora muito polêmica, para a compreensão da crise moral que assola a arena contemporânea, colocando-nos de fora da versão iluminista standard - e de seus subprodutos - que tem predominado na prática e na teoria moral, de tal forma que possamos vê-la por uma outra ótica e nos perguntemos pelos seus limites e problemas, se ela não nos levou a abandonar alguma coisa essencial para a sustentabilidade da racionalidade ética.

MacIntyre não se comporta como o garoto rebelde que depreda as vidraças à vista com seu estilingue, lançando suas pedras contra os males da modernidade iluminista e suas consequências para a teoria e a prática morais de nossa época. Sua reflexão filosófica visa, antes de tudo, ofertar uma alternativa razoável para os que se encontram cobertos pelos telhados de vidro do paradigma iluminista, tentando fazer que o enfrentamento entre posições incomensuráveis, como a que existe entre a dele e a posição universalista liberal, não constitua um diálogo de surdos e nem um pacífico debate no interior das águas calmas e necessárias de padrões neutros e acima das particularidades das tradições. Seu objetivo é que tal confronto venha a se constituir como um movimento inicial no reconhecimento das diferenças, coisa que, segundo ele, talvez seja um dos processos mais difíceis no debate filosófico, mas, ao mesmo tempo, o ponto de partida fundamental para qualquer superação dessas diferenças. E, nesse propósito, a compreensão da natureza real da racionalidade das tradições morais é um elemento primordial para possibilitar a afirmação das diferenças entre as tradições de pesquisa rivais e para compreender os processos iniciais de sua superação, ainda que precários e tortuosos, prenhes de incertezas.

Abstract: A characteristics of Contemporary Occidental Cultural machinery 
is making Ethics a central point concerning to the several spheres of human activity, including the action of mass media, crossing public health problems and economic questions, and coming to political activity, new technologies development and ecology. However, if this positively points us to a possible enhancement of human being before the viral pluralism in which we now live by showing how ethical requirements are more extensive each moment everywhere, on the other side this apparent consensus can not prevent us to take the question concerning what it is deeply mobilizing all that Cultural machinery around that subject. This paper presents the main axes of Alasdair MacIntyre's virtue ethics by showing how tradition, rationality and human good are articulated in order to offer an alternative to the difficulties of granting a moral rationality inside the Contemporary Occidental Cultural machinery, before the cultural force of Emotivism and also of relativism.

Keywords: virtues; tradition; rationality; human good; relativism.

\section{REFERÊNCIAS}

ANSCOMBE, E. Modern moral philosophy. In: CRISP, R.; SLOTE, M. (Eds.). Virtue ethics. Oxford: Oxford University Press, 1997. p. 26-44.

HALDANE, J. Verbete "MacIntyre". In: Canto-Sperber, M. (Ed). Dictionnaire de Philosophie Morale et Politique. Paris: PUF, 1994.

MACINTYRE, A. After virtue. A study in moral theory. [1981] 2. ed. London: Duckworth, 1985.

. Epistemological Crisis, dramatic narrative and the philosophy of science. The Monist, v. 60, n. 4, p. 453-72, 1977.

. Justiça de Quem? Qual Racionalidade? São Paulo: Loyola, 1991.

. The privatization of good. In: Delaney, C. F. (Ed.). The Liberalism-Communitarian debate. Lanham: Rowman \& Littlefield, 1994. 
. The relationship of Philosophy to its past. In: RORTY, R.; SCHNEEWIND, J. B.; SKINNER, Q. (Eds.). Philosophy in History. Cambridge: Cambridge University Press, 1984. p. 31-48.

MULHALL, S.; Swift, A. Liberals and communitarians. London: Blackwell, 1992.

OLIVEIRA, M. A. (Org). Correntes fundamentais da ética contemporânea. 2. ed. Petrópolis: Vozes, 2001.

PERES, D. T. (Org). Justiça, virtude e democracia. Salvador: Ed. Quarteto, 2006.

SHARKEY, R. Vertus, communautés et politique: la philosophie morale d'Alasdair MacIntyre. Nouvelle Revue Theologique, v. 123, p. 62-87, 2001. 